\title{
Design thinking e emoção: Uma relação de afinidade entre usuario e produto.
}

\author{
Prodanov-Juliane M. S. ${ }^{\text {a }}$; Figueiredo-Luiz Fernando G. ${ }^{\text {b }}$ \& Ourives-Eliete A. \\ ${ }^{a}$ Doutoranda - Universidade Federal de Santa Catarina (PosDesign,UFSC, Brazil) e \\ Juliane.msprodanov@gmail.com, \\ ${ }^{\mathrm{b}}$ Doutor - Universidade Federal de Santa Catarina (PosDesign,UFSC, Brazil) e \\ 1ffigueiredo2009@gmail.com \\ ${ }^{\mathrm{c}}$ Doutora - Universidade Federal de Santa Catarina (PosDesign,UFSC, Brazil) e \\ elieteourives@gmail.com
}

\section{Resumo}

Foi-se o tempo em que a pura estética era a parte mais importante em um produto, também não é mais a época onde só a função basta. Hoje, se está em um periodo que o conjunto da obra e uma boa experiência por parte dos usuários com relação a produtos que satisfaçam suas necessidades, se fazem essenciais. Às vezes, parece que há um esquecimento por parte dos profissionais envolvidos em colocar os usuários em primeiro plano, no centro de tudo. Com o Design Thinking, além de decretar-se o fim às velhas ideias, o usuário passa a ser prioridade, e não se está mais em busca daquilo que ele diz que quer ou que pelo menos, acha que quer, e sim, de um novo desafio: captar os seus sentimentos e até os seus sonhos. Busca-se neste trabalho analisar junto ao Design Emocional um estudo sobre a interação destes agentes - usuário e produto - para então, ficar mais fácil criar e entender à relação empática existente entre eles.

Palavras Chave:Design thinking, Design emocional, Design de experiência, Empatia Interação usuário/produto. 


\begin{abstract}
One is the time when the pure aesthetics was the most important part in a product also is not the only time where the function is sufficient. Today, we are in a period that the body of work and a good experience for users regarding products that meet their needs, make it essential. Sometimes it seems there is an oversight on the part of the professionals involved in putting users in the foreground, in the center of everything. With Design Thinking, and be declared an end to the old ideas, the user becomes a priority, and no one is more in search of what he says he wants or at least think you want, and yes, a new challenge: capture your feelings and even your dreams. Search in this work to analyze with the Emotional Design conduct a study on the interaction of these agents - user and product - can be easier to create and understand the empathic relationship existing between them.
\end{abstract}

Keywords: Design thinking; Emotional design; Experience design; Empathy; Interaction user/product.

\title{
1. Introdução
}

"[...] objetos atraentes fazem as pessoas se sentirem bem, o que por sua vez faz com que pensem de maneira mais criativa [...] ao fazer com que se torne mais fácil para as pessoas encontrar soluções para os problemas com que se deparam" (Norman, 2008, p.39).

Passou a época em que o designer pensava somente no produto a ser desenvolvido - sua estética e/ou função. Hoje, se está em um período que o conjunto da obra e uma boa experiência por parte dos usuários com relação a produtos que satisfaçam suas necessidades, se fazem essenciais. Às vezes, parece que há um esquecimento por parte dos profissionais envolvidos em colocar os usuários em primeiro plano, no centro de tudo.

Com o Design Thinking, além de decretar-se o fim às velhas ideias, o usuário passa a ser prioridade, e não se está mais em busca daquilo que ele diz que quer ou que pelo menos, acha que quer, e sim, de um novo desafio: captar os seus sentimentos e atÉ os seus sonhos.

A mudança do foco de atuação, colocando o usuário no centro de todo o processo de desenvolvimento de um projeto, melhora a relação homem-máquina, já que o sucesso de 
um produto no mercado depende da experiência interativa que ele - profissional - pode proporcionar, e que ele - usuário - pode usufruir.

A dificuldade de identificação das reais necessidades hoje faz com que o designretorne a focar o desenvolvimento de novos produtos ao ator principal deste processo, "o usuario", no processo de gerar e compreender à relação empática existente entre usuario e produto.

O proposito do designer hoje, é ajudar as pessoas a perceberem as suas reaisnecesidades que normalmente elas nem imaginava possuir.

A ausência de uma interpretação eficiente destas informações, o despreparo doprofissional em "olhar" o outro mas não ver, a dificuldade do usuario em identificar suacarencias, fazem deste processo de observação,analise e decodificação ineficiente.

Busca-se neste trabalho indagar bibliograficamente juntos, ao livro Design Thinking de Brown (2010) realizar um estudo sobre a interação destes agentes - usuário e produto - e como pode ficar maiS fácil criar e entender à relação empática existente entre eles.

\section{Design Thinking}

"O trabalho do designer é ,converter necessidade em demandae, é descobrir o que as pessoas querem e dar isso a elas" (Brown, 2010, p.37)

O termo "design" recebe varias interpretações, por este motivo hoje há uma dificuldade de definir que é Designer.

Nas leituras e pesquisas feitas nos livros e materiais de diversos autores da área percebeu-se como as opiniões são contrastantes.

Neste trabalho não houve a intenção de chegar a um consenso neste assunto e sim elencar ideias que seguem a cadeia de raciocínio do autor deste projeto.

Podem perceber como Lobach (2001) define design a seu ver:

“[...] co conceito de design compreende a concretização de uma ideia em forma de projetos ou modelos, mediante a construção e configuração e configuração resultando em um produto industrial passível de produção em série. O design estaria então realizando o processo configurativo" (Lobach,2001, p.16).

Podem perceber como Lobach (2001) define design a seu ver:

,[...]daí podemos deduzir que o design é uma ideia, um projeto ou um plano para a solução de um problema determinado. O design consistiria então na corporiflçação desta ideia para, 
Design thinking e emoção: Uma relação de afinidade entre usuario e produto.

com a ajuda dos meios correspondentes, permitir a sua transmissão aos outros. Já que nossa linguagem não é suficiente para tal, a confecção de croqui, projetos, amostras, modelos constitui o meio de tomar visualmente perceptível a solução de um problema ${ }^{\text {ee }}$ (Lobach,2001,p.16).

Baxter (2000) menciona em seu livro, o Design é responsável para a mudança e lançamento de novos produtos e para o desenvolvimento destes lançamentos ele resalta:

"O desenvolvimento de novos produtos é um atividade complexa, envolvendo diversos interesses e habilidades, tais como:

- Os consumidores desejam novidades, melhores produtos, a preços razoáveis;

- Os vendedores desejam diferenciações e vantagens competitivas;

- Os engenheiros de produção desejam simplicidade na fabricação e facilidade de montagem;

- Os designers gostariam de experimentar novos materiais, processos e soluções formais e;

- Os empresários querem poucos investimentos e retorno rápido do capital.

"Portanto, o desenvolvimento de novos produtos é necessariamente uma solução descompromisso. Diversos tipos de interesses devem ser satisfeitos.” (BAXTER, 2000, pag.2).

Para os designers thinkers, contudo, os comportamentos nunca são certos ou errados, mas são sempre significativos. Como enfatiza Brown (2010) em seu livro.

A dificuldade de identificação das reais necessidades hoje faz com que o design retorne a focar o desenvolvimento de novos produtos ao ator principal deste processo, "o cliente". Mas que uma tendência é uma filosofia de vida, forcar no ser humano, este é o pilar principal no Design thinking., como ressalta Brown:

"Precisamos aprender a colocar as pessoas em primeiro lugar" (Brown, 2010, pág. 37)

Muito tem sido debatido sobre este aspecto e a sua importância para a inovação. A pergunta recorrente quando levantado este assunto é “ porque é difícil verificar uma necessidade?”

O ser humano se adapta a situações e até mesmo chega a soluções engenhosas modificando objetos, processos do seu dia-a-dia sem perceber, porque está na essência do homem modificar, melhorar.

Quando o cliente/usuário do que ele precisa, se for perguntado o que realmente ele quer, como resultado não se conseguirá grandes ideais, inspirações e com isso inovação. 
A verdade meta do designer é ajudar as pessoas a perceberem as suas reais necesidades que normalmente elas nem imaginavam possuir, como afirma Brown ;

Para este fim, o autor resalta tres pontos de analise: Insight, observação, e empatia.

\section{1-Insight}

"É o achado proveniente da imersão, a identificação de uma oportunidade". (Vianna, 2013, p.67)

Sair e observar as verdadeiras experiências pessoais à medida que eles (clientes/usuários) improvisam no dia-a-dia.

Raramente as pessoas são capazes de dizer o que fazer, mas os seus comportamentos transmitem informações importantes da suas necessidades não atendidas.

O foco desta etapa para Vianna é aprender com a vida alheia, e o quadro abaixo demonstra o fluxo desta etapa do processo de imersão.

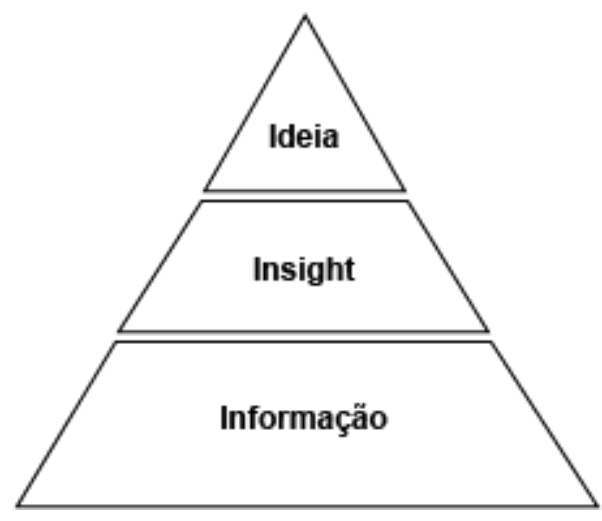

Fig 1 - (Vianna [et al.], 2012)

“É o achado proveniente da imersão, a identificação de uma oportunidade". (Vianna, 2013). Para um melhor desempenho nesta fase devesse munir se de conhecimento prévio, da forma de levantamento de dados, referente ao grupo, produto ou processo a ser estudado sem esquecer-se da analise do ambiente e da atmosfera para que a imersão no local seja eficiente. 
Design thinking e emoção: Uma relação de afinidade entre usuario e produto.

Após a coleta dos dados necessários pode-se chegar a identificação de oportunidades que resultaram em soluções geradas para atender a um ou mais insights.

\section{2-Observação}

"Necessitamos ver o que as pessoas não fazem e escutar o que elas não dizem" (BROWN, 2010, pág.41).

Esta fase consiste em sair da zona de conforto - de um escritório - e ir atrás de quem realmente importa, ou seja, do designer ir à procura dos seus clientes, ver como vivem, como se comportam e como se divertem. Observando-os no seu habitát será mais acertivo poder propor algo, que consequentemente, será experenciado da melhor forma possível. Brown(2010) afirma que é melhor ainda, ir atrás de usuários mais radicais - que não são o comum - para que se tenha insights novos e surpreendentes.

“[...] precisamos nos voltar aos extremos, aos locais em que esperamos encontrar usuários "radicais", que vivem de forma diferenciada, pensam de forma diferenciada e consomem de forma diferenciada - um colecionador que tem 1.400 Barbies, por exemplo ou um ladrão profissional de carros" (BROWN, 2010, p.41-42).

Vianna (2013), define esta fase - a de observação - como sendo um processo de "imersão", onde a equipe responsável pelo desenvolvimento de um projeto imerge no contexto do problema tanto do ponto de vista da empresa - o cliente - quanto do usuário final do produto - o cliente do cliente. Processo este que pode ser dividido em dois: imersão preliminar e imersão em profundidade.

A imersão preliminar serve como base para uma investigação mais profunda, definindo escopo de projeto, identifcação de usuários e áreas a serem exploradas. Já a imersão em profundidade busca identificar necessidades e oportunidades em busca de soluções, utilizando-se de planos de pesquisa, técnicas oriundas da antropologia tais como, entrevistas, sessões generativas etc. As técnicas devem ser escolhidas em função daquilo que se deseja obter no desenvolvimento do projeto e na construção do produto final. A seguir (Fig.02), pode-se perceber através de uma síntese do processo de imersão, as hierarquias - da preliminar a mais profunda - tanto da ação e percepção das pessoas, quanto de técnicas, e ainda, de conhecimentos gerados frutos da imersão. Se começar pelo que as pessoas dizem e pensam só vai revelar algo explícito ao passo que se tentar chegar ao que elas sabem, sentem e sonham vai acabar revelando quais as suas reais necessidades. 


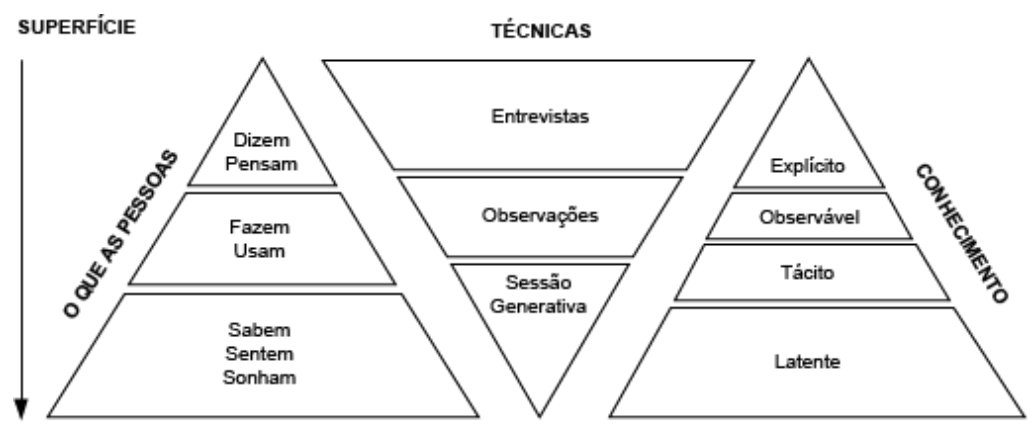

PROFUNDIDADE

Fig 2 - Sintese do processo de imersão (Sleeswijkvisser et al. in Vianna et a, 2013).

\section{3-Empatia}

"[...] é a tentativa de ver o mundo através dos olhos dos outros, de compreender o mundo por meio das experiências alheias e de sentir o mundo por suas emoções" (BROWN, 2010, pág.47)

Para começar a dissertar sobre empatia é preciso rever qual a grande missão do design thinking, que segundo Brown (2010) "é traduzir observações em insights, e estes em produtos e serviços para melhorar a vida das pessoas". Melhorar a vida das pessoas é fazer com que a relação usuário/produto seja uma boa experiência.

"A empatia é o hábito mental que nos leva a pensar nas pessoas como pessoas, e não como ratos de laboratório ou desvios-padrão. Se formos "tomar emprestada" a vida dos outros para inspirar novas ideias, precisamos começar reconhecendo que seus comportamentos aparentemente inexplicáveis representam diferentes estratégias para lidar com o mundo confuso, complexo e contraditório no qual as pessoas vivem" (Brown, 2010, p.46-47).

É difícil projetar algo para pessoas com os quais não se tem convívio, que não se conhece seus anceios, suas necessidades, seus modos de viver, suas localidades, e tantos outros fatores que podem afetar suas interações e percepções sobre os produtos.

Vianna (2013) mostra em seu livro um "mapa de empatia", onde organiza todas as informações coletadas na fase de imersão - observação - para se entender contextos, comportamentos, preocupações e aspirações do usuário. Este mapa é dividido em seis áreas, com seis perguntas, visando um maior entendimento do usuário investigado. São elas: 
Design thinking e emoção: Uma relação de afinidade entre usuario e produto.

1. "O que o cliente enxerga?" Descrição do que o cliente vê em seu ambiente; 2. "O que o cliente ouve?" Descrição de como o ambiente influencia o cliente; 3. "O que o cliente realmente pensa e sente?” Exercício visando entender como funciona a cabeça do cliente; 4. "O que o cliente diz e faz?" Exercício visando entender de que forma o cliente se comporta em público e o que ele pensa; 5. "Quais são as dificuldades do cliente?” Descrição dos empecilhos notados pelo cliente durante a experiência; 6."Quais são as conquistas do cliente?" Descrição dos aspectos positivos e promissores do ponto de vista do cliente (Vianna et al., 2013).

\section{Design Emocional}

[...] o sistema emocional muda a maneira como o sistema cognitivo opera (Norman, 2008, p.38).

A cognição interpreta o mundo, levando a aumentar a compreensão e o conhecimento. $\mathrm{O}$ afeto, que inclui emoção, é um sistema de julgamento do que é bom ou mau, seguro ou perigoso. Isso cria juízos de valor que nos permitem sobreviver melhor (NORMAN, 2008, p. 40).

A emoção é particular, ou seja, uma determinada experiência pode agradar a uma pessoa e a outra não. E um bom produto precisa agradar o máximo possível de usuários. Norman (2008) define três níveis de design que afetam a emoção: visceral, comportamental e reflexivo.

$\mathrm{O}$ visceral diz respeito a aparência e a primeira impressão que determinado produto cause em uma pessoa. O comportamental é sobre a experiência de uso sobre o produto, que pode levar em conta a função, o desempenho e a usabilidade. E o terceiro, o reflexivo, é que dá conta da emoção e cognição. Nos dois primeiros existe apenas o afeto, sem interpretação ou consciência. Norman (2008) sintetiza da seguinte maneira:

Design Visceral - Aparência;

Design Comportamental - Prazer e efetividade de uso;

Design Reflexivo - Auto-imagem, satisfação pessoal, lembranças (Norman, 2008, pg. 59).

\section{Interação entre usuário e produto}

Para que haja uma interação entre um usuário com um produto qualquer, o designer tem de estar envolvido na criação deste artefato, e conforme Bonsiepe (1997), o papel central do 
designer é projetar a interface. E mais, “o design é o domínio no qual se estrutura a interação entre usuário e produto, para facilitar ações efetivas” (Bonsiepe, 1997, p.31). Ou seja, para uma boa experiência ${ }^{1}$ por parte de um indivíduo acerca de um produto, o designer precisa estar consciente das ferramentas disponíveis para produção, para então, poder propor uma interface, tendo em vista seu público-alvo e necessidades. Que é o que propõe o diagrama ontológico do design (Fig. 03):

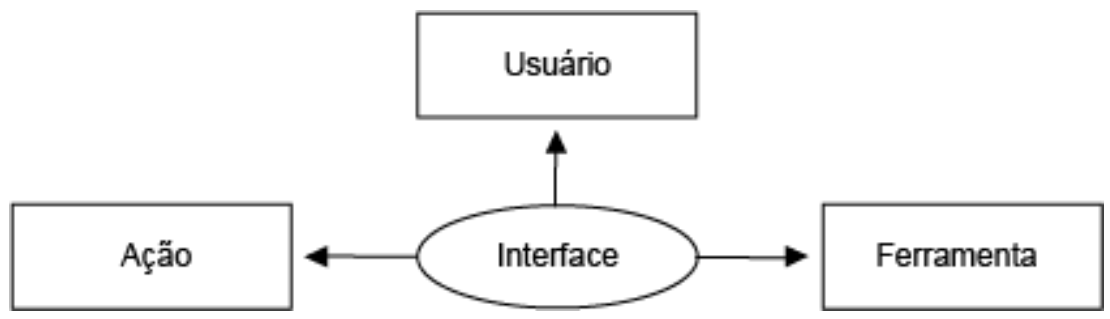

Fig 3 - Diagrama ontológico do design (Bonsiepe, 1997).

Com a intenção descobrir o nível de satisfação que as pessoas têm ao interagir com um produto, Bonapace (2002) criou um quadro com níveis de prioridade:

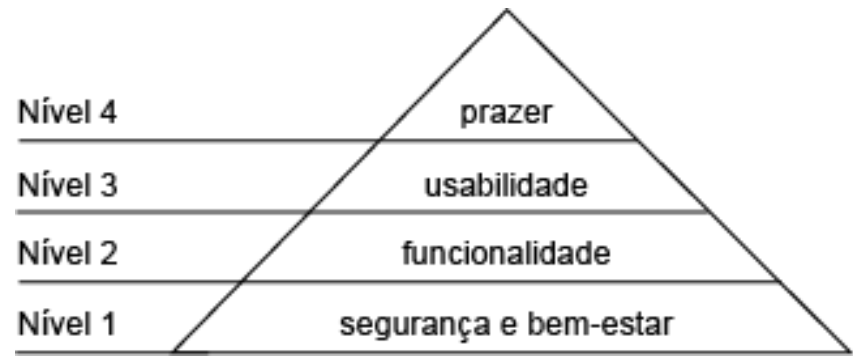

Fig 4 - Hierarquia de necessidade dos usuários em interação com produtos (Bonapace, 2002).

\footnotetext{
1 "A experiência é moldada pelas características do usuário (por exemplo, personalidade, habilidades, fundo, valores culturais e motivos) e as do produto (por exemplo, forma, textura, cor e comportamento). Todas as ações e processos que estão envolvidos, tais como ações físicas e processos perceptivos e cognitivos (por exemplo, perceber, exploração, utilização, lembrando, comparando, compreensão e), vai contribuir para a experiência (ver também Dewey, 1980). Além disso, a experiência é sempre influenciado Pelo contexto (por exemplo, físicas, sociais, econômicos), em que a interação ocorre" (DESMET apud LOPES, 2012).
} 
Segundo Moles (1981), a relação entre o homem e os objetos passa por diversos estágios: inicia pelo desejo, que é suprido pela aquisição, em seguida pela descoberta e pela relação afetiva com ele. Depois desse estágio, ocorre um declínio da relação e o objeto pode ser conservado, substituído ou descartado.

\section{Considerações Finais}

"O resultado é que tudo o que fazemos tem, ao mesmo tempo, um componente cognitivo e um componente afetivo - cognitivo para atribuir significado, afetivo para atribuir valor. Não se pode escapar do afetivo: ele está sempre presente" (NORMAN, 2008, p.45-46).

Observado a trajetoria do design ao longo da historia, nota-se que hoje está se retornando ao conceito de colocar o usuário como sendo o foco de todo o desenvolvimento de produtos ou servicos, com uma visão mais evoluída e contemporânea, mas ele volta a ser o centro das atenções. E assim como Burdek (2006) refere-se a Horst Oelke (1978), atuante na antiga Republica Democrata alemã, evidencia-se a retomada do pensamento anterior a revolução industrial, "que o design deveria atuar tambèm para satisfazer as necessidades da vida social e individual". (Burdek, 2006)

Atualmente compreende se que os problemas que aflingem o bem-estar das pessoas são de natureza diversa, que é preciso mapear a cultura, os contextos, as experiências pessoais e os processos na vida dos indivíduos para ganhar uma visão mais ampla e assim melhor identificar as reais necessidades de cada um.

Ao agregar o ponto de vista humano à tecnologia e a um produto economicamente factível, o designer hoje possui o intuito de não somente fornecer um produto adequado para as necessidades do usuario mas proporcionar a experiência de uso prazeroso, criando uma ligação afetiva do usuário ao produto.

Conclui-se, portanto, que todo e qualquer resultado é fruto de uma interação e colaboração. Um trabalho conjunto entre designers e usuários, criadores e consumidores, em busca de uma boa experiência, seja ela funcional, visual, sensorial ou emocional, visando a total empatia. 


\section{Referências}

Baxter, M. R. (2000) Projeto de produto: guia prático para o design de novos produtos. São Paulo: Blueher,

Bonapace, L.. (2002) Linking Product Properties to Pleasure: The Sensorial Quality Assessment Method - SEQUAM. In: GREEN, W; JORDAN, P. (Eds.). Pleasure with Products, beyond usability. London: Taylor \& Francis,. p. 189-217.

Bonsiepe, G..( 1997). Design: Do Material ao Digital. Tradução Cláudio Dutra. Florianópolis: FiES/IEL,

Brown, Tim. (2010). Design thinking: uma metodologia poderosa para decretar o fim das velhas ideias. Rio de Janeiro: Elsevier,

Burdek. Bernhard E. (2006). História, teoria e prática do design d e produtos. São Paulo: Edgard Blücher.

Cardoso, N. Pizzetti; Pereira, A. T. C.. (2011). Design de experiência como estímulo para o desenvolvimento de hipermídias voltadas a satisfação do usuário. Congresso Nacional de Ambientes Hipermídia para Aprendizagem.

Duffy, V. C.; Ramos, M.; Silva. (2014). O desafio de transformar a criatividade em inovação: o caso do rio criativo. Int. J. Knowl. Eng. Manag., ISSN 2316-6517, Florianópolis, v. 3, n.5, p. $242-$ 258, mar2014/jun2014.

Frascara, J. (2002). Design and the social sciences: making connections. New York: Taylor \& Francis - Contemporary Trends Institute.

Lobach, B.; Van Camp, F. (2001). Design industrial: bases para a configuração dos produtos industriais. São Paulo (SP): Edgard Blücher.

Lopes, E. C. (2017). UMA (RE)VISÃO DO CONCEITO DE EXPERIÊNCIA DO USUÁRIO: a experiência como narrativa. Especialização em Comunicação Digital. Escola de Comunicações e Artes. Universidade de São Paulo, 2012. Disponível em: <http://grupoecausp.com/digicorp/wp-content/uploads/2014/03/ELISABETE-CRISTINA-LOPES1.pdf> Acesso em: 15 Mar 2017.

Norman, D. A. (2008). Design emocional: por que adoramos (ou detestamos) os objetos do dia-a-dia. Rio de Janeiro: Rocco.

Queiroz, S. G.; Cardoso, C. L.; Gontijo, L. A. (2017). Design Emocional e Semiótica: caminhos para obter respostas emocionais dos usuários. Maxwell, Rio de Janeiro, 2009. Disponível em: $<$ http://www.maxwell.lambda.ele.puc-rio.br/16496/16496.PDF>. Acesso em: 15 Mar 2017.

Scorali, S. H. P. (2008). Design e emoção: um modelo de círculos de referências de emoções em produtos. Bauru, $64 \mathrm{f}$.

Silva, C. A. da. (2011). Design emocional: afetos positivos e negativos nas interações com ambientes web. 231 f. Dissertação (Mestrado) - Curso de Programa de Pós- Graduação em Design e 
Design thinking e emoção: Uma relação de afinidade entre usuario e produto.

Expressão Gráfica, Departamento de Centro de Comunicação e Expressão, Universidade Federal de Santa Catarina, Florianópolis, 2011. Disponível em: $<$ https://repositorio.ufsc.br/bitstream/handle/123456789/96089/293369.pdf?sequence=1>. Acesso em: 15 Mar 2017.

Vianna, M. et al. (2012). Design thinking: inovação em negócios. Rio de Janeiro: MJV Press. 